Dokuz Eylül Üniversitesi-Mühendislik Fakültesi

Fen ve Mühendislik Dergisi

Cilt 19, Sayı 56, Mayıs 2017
Dokuz Eylul University-Faculty of Engineering Journal of Science and Engineering Volume 19, Issue 56, May2017

DOI: $10.21205 /$ deufmd. 2017195647

\title{
Fotovoltaik Güneş Pillerinde Saydam Ön Kontak Olarak Kullanılabilecek ZnO:Al Filmlerinin İncelenmesi
}

\author{
Sema KURTARAN *1 , , İdris AKYÜZ ${ }^{1}$, Ferhunde ATAY ${ }^{1}$ \\ 1Eskişehir Osmangazi Üniversitesi, Fen Edebiyat Fak., Fizik Bölümü, 26480, Eskişehir
}

(Alınış / Received: 11.07.2016, Kabul / Accepted: 10.11.2016, Online Yayınlanma / Published Online: 02.05.2017)

Anahtar Kelimeler Al katkılı ZnO, Optik özellikler, XIK, AFM, EDS

Özet: $\mathrm{Bu}$ çalışmada, fotovoltaik güneş pillerinde kullanılan $\mathrm{ZnO}$ filminin fiziksel özelliklerini geliştirmek amacı ile Al elementi (\% 8 hacimsel oran) ile katkılama işlemi yapılmıştır. ZnO:Al filmleri Ultrasonik Kimyasal Püskürtme tekniği ile üretilmiş ve fiziksel özelliklerini iyileştirmek için hava ortamında tavlanmıştır. X-ışını kırınımı analizleri filmlerin polikristal formda ve wurtzite hekzagonal tipi kristal yapıya sahip olduklarını göstermiştir. Elektriksel özdirenç değerlerinin tavlama işlemi sonrasında arttığı belirlenmiştir. Atomik kuvvet mikroskobu ile filmlerin yüzey morfolojisi ve pürüzlülükleri incelenmiştir. Filmlerin görünür bölgede yüksek geçirgenliğe sahip oldukları saptanmıștır. Ayrıca, filmler için kırılma indisi $(n)$ ve sönüm katsayısı $(k)$ değerleri de rapor edilmiştir. Filmlerin optik bant aralığı değerleri optik metot yardımı ile belirlenmiştir. Sonuç olarak, tavlama sıcaklığının elde edilen filmlerin optik, yapısal, elektriksel ve yüzeysel özellikleri üzerinde önemli bir etkisi olduğu saptanmıştır.

\section{Investigation of Zn0:Al Films As Transparent Front Contact For Photovoltaic Solar Cells}

Keywords

Al doped $\mathrm{ZnO}$, Optic properties, XRD,

AFM,

EDS

\begin{abstract}
In this work, doping with Al element (8\% volume ratio) has been carried out to improve the physical properties of $\mathrm{ZnO}$ film used in photovoltaic solar cells. ZnO:Al films have been produced by ultrasonic spray pyrolysis technique and annealed in air to improve their physical characteristics. X-ray diffraction reveals that the films are polycrystalline having wurtzite hexagonal type crystal structure. Electrical resistivity values of the films have been increased after annealing process. Surface morphologies and roughness values of the films have been investigated by atomic force microscopy. Films are highly transparent in the visible region. Also, refractive index, $n$, and extinction coefficient, $k$, values for $\mathrm{ZnO}$ films have been reported. Optical band gap values have been determined using optical method. Finally, it has been concluded that annealing temperature has an important effect on the optical, structural, surface and electrical properties of the deposited films.
\end{abstract}


S. Kurtaran vd. / Fotovoltaik Güneş Pillerinde Saydam Ön Kontak Olarak Kullanılabilecek ZnO:Al Filmlerinin İncelenmesi

\section{Giriş}

Günümüzde sürekli gelişen ve yenilikler arayan optoelektronik teknolojisinde popüler olan indiyum-kalay oksit (ITO) malzemesine alternatif olabilecek $\mathrm{SnO}_{2}$, $\mathrm{ZnO}, \mathrm{CdO}, \mathrm{Zn}_{2} \mathrm{SnO}_{4}, \mathrm{CuAlO}_{2}, \mathrm{SrTiO}_{3}$ gibi saydam iletken oksitlerin üretilmesi ve özelliklerinin incelenmesi üzerine yapılan çalışmalar her geçen gün artmaktadır [1]. Bunlar arasında olan $\mathrm{ZnO}$ filmleri, optoelektronik aygitlar, gaz sensörleri, ışık yayan diyotlar, güneş pilleri ve optik fiberler için uygun optik ve elektriksel özelliklere sahip olmaları nedeniyle teknolojik uygulamalarda cazip hale gelmişlerdir [2-4]. ZnO oda sıcaklığında büyük yasak enerji aralığına sahip olması nedeniyle güneş pili uygulamalarında saydam ön kontak olarak geniş bir yer bulmaktadır. Bu uygulamalarda kullanılacak materyaller düşük özdirenç ve yüksek geçirgenlik gibi iki temel özelliğe sahip olmalıdır. ZnO filmlerinin belirtilen özelliklerini geliştirebilmek için yaygın olarak kullanılan yöntemler arasında katkılama işlemi de yer almaktadır. Birçok çalışmada Ga [5-7], In [8, 9], Mn [10] Cd [11], Mg [12-14], Co [15, 16], Sn [17] ve Al [18-27] gibi elementler ile katkılama işlemi yapılmıştır. ZnO filmlerinin elde edilmesinde saçtırma [7, 26, 27], pulslu lazer çöktürme [24, 26, 29], kimyasal banyo çöktürme $[18,23,30]$ ve ultrasonik kimyasal püskürtme $[3,4,14$, 16, 28, 31] gibi çeşitli teknikler kullanılmıştır. $\mathrm{Bu}$ teknikler arasında ultrasonik kimyasal püskürtme (UKP), vakum gerektirmeyen ve daha geniş yüzeyli filmlerin elde edilmesini sağlayan basit, ekonomik ve aynı zamanda farklı elementlerin katkılanmasına izin veren uygun bir yöntemdir [4, 32, 33]. Bunun yanında isıl tavlama işlemi ile de film karakteristikleri iyileștirilebilir [3, 3442].

Literatürde Al katkılı ZnO filmleri için farklı katkı oranlarında çalışmalar mevcuttur $[3,18,23,25]$. Al atomik oranının $\% 5^{\prime}$ in altında kaldığı durumlarda umut vaat eden $\mathrm{ZnO}$ filmleri üretilebileceğini, aksi halde $\mathrm{Al}$ elementine bağlı ikincil fazların ve kusurların ZnO film yapısını bozacağını düşünmekteyiz. Buradan yola çıkarak çalıșmamızda $\mathrm{Al}$ atomik oranını bu aralıkta tutmak adına, hacimsel oran olarak \%8 Al kaynağı toplam püskürtme çözeltisine eklenerek Al katkılı $\mathrm{ZnO}$ filmleri elde edilmeye çalışılmıştır. Bu çalışmadaki amacımız, ekonomik bir yöntem olan UKP yöntemi ile $\mathrm{Al}$ elementi için $\% 5^{\prime}$ in altında atomik ağırlığa sahip katkılı $\mathrm{ZnO}$ filmlerini üretmek ve elde edilen filmlerin bazı fiziksel özellikleri üzerine isll tavlama işleminin etkisini araștırmaktır.

\section{Materyal ve Metot}

$\mathrm{Bu}$ çalışmada $\mathrm{ZnO}$ filmleri $350 \pm 5$ ำ taban sicaklığında mikroskop cam tabanlar üzerine UKP tekniği kullanılarak elde edilmiștir. UKP sisteminin detayları daha önceki çalışmalarda verilmiştir [43]. $\mathrm{ZnO}$ filmlerinin üretilmesinde $\mathrm{Zn}$ ve Al kaynağı olarak $\left[\mathrm{Zn}\left(\mathrm{CH}_{3} \mathrm{COO}\right)_{2} 2 \mathrm{H}_{2} \mathrm{O}\right]$ (çinko asetat; $0.1 \mathrm{M}$ ) ve $\left[\mathrm{AlCl}_{3} .6 \mathrm{H}_{2} \mathrm{O}\right]$ (alüminyum klorür; $0.1 \mathrm{M}$ ) kimyasalları seçilmiştir. Çözücü olarak deiyonize su kullanılmıştır. Başlangıç püskürtme çözeltisi $(100 \mathrm{ml})$, hazırlanan bu çözeltilerin üretilecek filmin katkı oranına bağlı olarak $92 \mathrm{ml} \quad \mathrm{Zn}$ $\left(\mathrm{CH}_{3} \mathrm{COO}\right)_{2} \cdot 2 \mathrm{H}_{2} \mathrm{O}$ ve $8 \mathrm{ml} \quad \mathrm{AlCl}_{3} \cdot 6 \mathrm{H}_{2} \mathrm{O}$ olacak şekilde karıştırılması sonucu elde edilmiştir. Tortu oluşumunu önlemek ve homojen karışım sağlamak için hazırlanan püskürtme çözeltisi $20 \mathrm{dk}$ manyetik karıştırıcı ile karıştırılmıştır. Taban sıcaklığını sağlamak için $5 \mathrm{~kW}$ gücünde elektrikli ısıtıcı kullanılmıştır. Ultrasonik püskürtme başlığının titreşim frekansı $100 \mathrm{kHz}$ ve ortalama damlacık boyutu $20 \mu \mathrm{m}^{\prime}$ dir. Taşıyıcı gaz olarak hava (1 bar) kullanılmıştır. Cam tabanlar ile püskürtme başlı̆̆ $35 \mathrm{~cm}$ olarak ayarlanmıștır. $100 \mathrm{ml}^{\prime}$ lik 
S. Kurtaran vd. / Fotovoltaik Güneş Pillerinde Saydam Ön Kontak Olarak Kullanılabilecek ZnO:Al Filmlerinin İncelenmesi

toplam püskürtme çözeltisi, $5 \mathrm{ml} / \mathrm{dk}$ akış hızında $20 \mathrm{dk}$ süreyle püskürtülmüştür. Püskürtme işlemi bittikten sonra filmler soğumaya bırakılmıştır. Üretilen Al katkılı ZnO filmleri iki farklı sıcaklıkta $\left(400{ }^{\circ} \mathrm{C}\right.$ ve $\left.500{ }^{\circ} \mathrm{C}\right) \quad 150 \mathrm{dk}$ hava ortamında ısıl işleme tabi tutulmuştur. Filmler AZ8 (1sıl ișlemsiz), AZ8-400 (400 ${ }^{\circ} \mathrm{C}$ isıl tavlama) ve AZ8-500 (500 ${ }^{\circ} \mathrm{C}$ isıl tavlama) şeklinde kodlanmıştır.

Teknolojik uygulamalarda kullanılacak olan yariletken ince filmlerin basit ve ekonomik tekniklerle üretilmelerinin yanında fiziksel özelliklerinin iyi analiz edilmeleri de oldukça önemlidir. $\mathrm{Bu}$ çalışmada üretilen $\% 8 \mathrm{Al}$ katkılı $\mathrm{ZnO}$ filmlerinin yapısal özelliklerini incelemek için, X-ışını kırınım (XIK) desenleri "Rigaku X-Ray Diffractometer Model" cihazında $\lambda=1.5406 \AA$ dalgaboylu $\mathrm{CuK}_{\alpha}$ ışını kullanılarak $30^{\circ} \leq 2 \theta \leq 70^{\circ}$ aralığında alınmıștır. Filmlerin kalınlıklarını ve optik sabitlerini belirlemek için "OPTS9000 Spektroskopik Elipsometre" cihazı kullanılmıştır. Ayrıca "Shimadzu-2550UV-VIS Spektrofotometre" cihazı ile geçirgenlik spektrumları alınmış ve optik bant aralıkları optik metot ile belirlenmiştir. ZnO filmlerinin yüzey morfolojisi "Park Systems XE 100 model" Atomik Kuvvet Mikroskobu (AKM) ile "temassız" modda oda sicaklığında alınmıştır. Ayrıca pürüzlülük değerleri "XEI version 1.7.1" yazılımı kullanılarak belirlenmiştir. Elemental analizlerini yapmak için JEOL JSM-5600LV model taramalı elektron mikroskobu (SEM) kullanılmıştır. Elektriksel özdirenç değerleri Keithley 2601 Lucas Labs. Pro 4 dört uç sistemi ile belirlenmiştir.

\section{Bulgular}

\subsection{Elemental Analiz}

Enerji dağılımlı X-ışını spektroskopisi (EDS) kullanılarak Al katkılı ZnO filmlerinin kimyasal bileşimi hakkında bilgi edinilmiștir. Filmlerin elemental analizleri sonucunda elde edilen atomik ağırlıklar Tablo 1' de verilmektedir. Katı filmler içerisinde beklenen $\mathrm{Zn}, 0$ ve $\mathrm{Al}$ elementlerinin yapıda bulunduğu görülmektedir. Başlangıç püskürtme çözeltisine $\% 8$ hacimsel oranında $\mathrm{AlCl}_{3} .6 \mathrm{H}_{2} \mathrm{O}$ eklendiğinde, atomik olarak \%3 oranında Al katkılı ZnO filmleri elde edilebildiği görülmüștür. $\mathrm{Bu}$ durum çalışmamızda önceden öngörüldüğü gibi Al elementine bağlı ikincil fazlardan ve kusurlardan kaçınmak adına olumludur. X-ışını kırınımı analizlerinde de $\mathrm{Al}$ elementine bağlı herhangi bir ikincil faza rastlanılmamıştır. Tavlama işlemi ile $\mathrm{Al}$ elementinin yapıdaki oranı artmıştır. Ayrica saydam iletken oksit olan $\mathrm{ZnO}$ filmlerinde beklenildiği gibi oksijen eksikliği ve Zn fazlalığı görülmektedir.

Tablo 1. Al katkılı ZnO filmlerinin EDS analizleri.

\begin{tabular}{|c|c|c|c|}
\hline Malzeme & $\begin{array}{c}\text { Zn } \\
\text { (\%) }\end{array}$ & $\begin{array}{c}\text { 0 } \\
\text { (\%) }\end{array}$ & $\begin{array}{c}\text { Al } \\
\text { (\%) }\end{array}$ \\
\hline AZ8 & 63.17 & 33.85 & 2.98 \\
\hline AZ8-400 & 60.42 & 36.42 & 3.16 \\
\hline AZ8-500 & 62.77 & 33.71 & 3.52 \\
\hline
\end{tabular}

\subsection{Yapısal Özellikler}

Al katkılı ZnO filmlerinin XIK desenleri Şekil 1'de verilmektedir. Tüm desenlerde gözlenen farklı şiddet ve genişliklere sahip pikler, filmlerin polikristal yapıda oluştuğunun bir göstergesidir. Bu piklere ait kırınım açıları $(2 \theta)$, düzlemler arası uzaklıkları $(d)$ ve miller indisleri Tablo 2' de verilmektedir. Şekil 1 ve Tablo 2 incelendiğinde, filmlerin hegzagonal wurtzite $\mathrm{ZnO}$ fazında oluştuğu ve $\mathrm{Al}$ elementine veya oksitlerine ait herhangi bir fazın var olmadığı belirlenmiștir. Ayrica (100), (002), (101), (102), (110), (103) ve (112) karakteristik ZnO düzlemlerinden olan yansımalara ait piklerin var olduğu gözlenmiştir. Tüm filmler için (002) yönelimlerine ait pikin baskın büyüme yönü olduğu dikkat çekmektedir. Isıl tavlama işlemine tabi 
S. Kurtaran vd. / Fotovoltaik Güneş Pillerinde Saydam Ön Kontak Olarak Kullanılabilecek ZnO:Al Filmlerinin İncelenmesi

tutulan filmlerin XIK desenleri incelendiğinde, en çok dikkati çeken nokta AZ8-400 filminde kristalleşme seviyesinin iyileștiği ve özellikle (002) pikinin şiddetinde artış olduğudur. Bu durum, isıl tavlama işleminin etkisi ile oksijen elementinin yapıdaki oksijen boşluklarının $\left(V_{0}\right)$ yerine geçmesinden kaynaklanabilir. Böylece tane boyutlarında artış ve tane sınırlarındaki oksijen miktarında azalma meydana gelecektir. Ancak tavlama sıcaklığının artırılması ile birlikte AZ8-500 filminde pik şiddetlerinin azaldığı ve yarı pik genişliklerinin az da olsa arttığı göze çarpmaktadır. Bu durum $500{ }^{\circ} \mathrm{C}$ tavlama sıcaklığının filmlerin kristalleşme seviyelerinin bozulması yönünde bir etki yarattığını göstermektedir. Bu filmlerde oksijen elementinin yapıdaki oksijen boşluklarının yerine yerleşmesi yanında oksijen ara durum $\left(\mathrm{O}_{i}\right)$ olarak ya da tane sınırlarına yerleşerek yapıda yer bulması, kristalleşme seviyesinin bozulmasına neden olarak gösterilebilir.

Al katkılı ZnO filmlerinin yapısal özellikleri hakkında ayrıntılı bilgi elde edebilmek için XIK desenlerinden elde edilen veriler kullanılarak; tane boyutları $(D)$, dislokasyon yoğunluğu $(\delta)$ ve makro gerilmeleri $(<e>)$ hesaplanmıştır. Üretilen filmlerin tane boyutlarının belirlenmesinde Scherrer formülü kullanılmıştır.

$D=\frac{0.9 \lambda}{\beta \cos \theta}$

Burada $D$ tane boyutu, $\beta$ ilgili kristal yönü için radyan olarak yarı pik genişliği, $\theta$ Bragg açısı ve $\lambda$ kullanılan X-ışınının dalgaboyudur [44]. Bir malzemenin belli bir kısmında bulunan dislokasyonların sayısının bir ölçüsü veya birim alanı kesen dislokasyon çizgilerinin sayısı dislokasyon yoğunluğu $(\delta)$ olarak bilinir. $\delta=\frac{}{D^{2}}$

Minimum $\delta$ değeri için $n=1$ alınır. Küçük $\delta$ değerleri malzemenin kristalleşme seviyesinin iyi olduğunun göstergesidir [45]. XIK desenlerinde gözlenen piklerin pozisyonlarındaki hafif kaymalar sıkışmış/genişlemiş örgü düzlemlerinin varlığına işarettir ve aşağıdaki denklem kullanflardk irdelenebilir.

Burada $<e>$ malzemedeki makro gerilmeleri, $d$ deformasyon halinde ve $d_{0}$ ise deformasyon olmadığ durumdaki düzlemler arası mesafeyi göstermektedir [46]. Tüm filmlerin (002) yönelimi için hesaplanan tane boyutu $(D)$, dislokasyon yoğunluğu $(\delta)$ ve makro gerilme $(<e>)$ değerleri Tablo 3' te verilmektedir. Buna göre, tane boyutlarının 44-49 nm arasında değiștiği ve AZ8-400 numunesinde tane boyutunda artış olduğu göze çarpmaktadır. Bu durum yarı pik genişliklerinin de azalmasına işarettir ve kristal yapının iyileștiğinin bir göstergesidir. Ayrıca Tablo 3' te görüldüğü gibi, AZ8-400 filminin $\delta$ değerinin de küçük olması, $400{ }^{\circ} \mathrm{C}$ tavlama sıcaklığının filmlerin kristalleşme seviyelerinin iyileşmesi yönünde bir etki yarattığını işaret etmektedir. Bir kristalde piklerin pozisyonlarında kaymalar olduğunu gösteren makro gerilmeler $(<e>)$ de kristal yapı üzerinde önemli etkiye sahiplerdir. Kristalde deformasyonun az olduğu küçük makro gerilme değerlerinden öngörülebilir. En küçük makro gerilme değerinin AZ8-400 filmi için elde edildiği görülmektedir. $400{ }^{\circ} \mathrm{C}$ sıcaklıktaki tavlama işlemi ile örgü düzlemlerindeki genişlemenin azaldığ söylenebilir. 
S. Kurtaran vd. / Fotovoltaik Güneş Pillerinde Saydam Ön Kontak Olarak Kullanılabilecek ZnO:Al Filmlerinin İncelenmesi
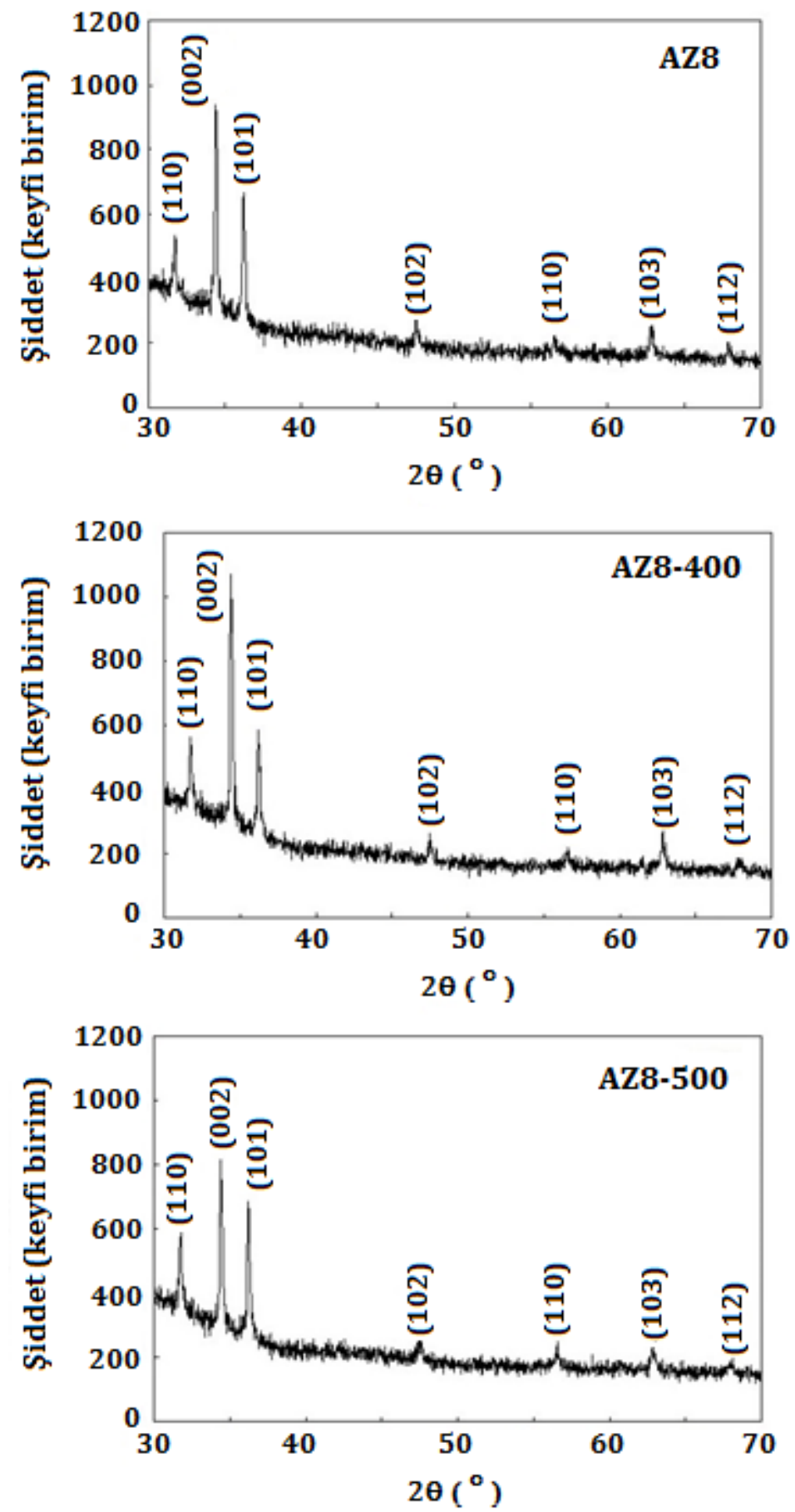

Şekil 1. Al katkılı ZnO filmlerinin XIK desenleri. 
S. Kurtaran vd. / Fotovoltaik Güneş Pillerinde Saydam Ön Kontak Olarak Kullanılabilecek ZnO:Al Filmlerinin İncelenmesi

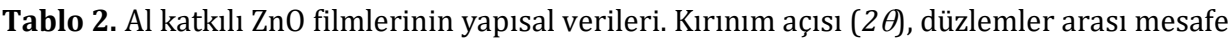
$(d)$, Miller indisleri $(h k l)$.

\begin{tabular}{|c|c|c|c|c|c|}
\hline Malzeme & $2 \theta\left({ }^{\circ}\right)$ & $d(\bar{\AA})$ & $\begin{array}{l}2 \theta_{0}\left({ }^{\circ}\right) \\
\text { (ASTM) }\end{array}$ & $\begin{array}{c}\text { do }(\hat{A}) \\
\text { (ASTM) }\end{array}$ & (hkl) \\
\hline \multirow{7}{*}{ AZ8 } & 31.72 & 2.8185 & 31.77 & 2.8143 & $\left(\begin{array}{lll}1 & 0 & 0\end{array}\right)$ \\
\hline & 34.40 & 2.6050 & 34.42 & 2.6033 & $\left(\begin{array}{lll}0 & 0 & 2\end{array}\right)$ \\
\hline & 36.21 & 2.4784 & 36.25 & 2.4759 & $\left(\begin{array}{lll}1 & 0 & 1\end{array}\right)$ \\
\hline & 47.52 & 1.9119 & 47.53 & 1.9111 & $\left(\begin{array}{lll}1 & 0 & 2\end{array}\right)$ \\
\hline & 56.62 & 1.6244 & 56.60 & 1.6247 & $\left(\begin{array}{lll}1 & 1 & 0\end{array}\right)$ \\
\hline & 62.92 & 1.4759 & 62.86 & 1.4771 & $\left(\begin{array}{lll}1 & 0 & 3\end{array}\right)$ \\
\hline & 68.05 & 1.3765 & 67.96 & 1.3781 & $\left(\begin{array}{lll}1 & 1 & 2\end{array}\right)$ \\
\hline \multirow{7}{*}{ AZ8-400 } & 31.74 & 2.8165 & 31.77 & 2.8143 & $\left(\begin{array}{lll}1 & 0 & 0\end{array}\right)$ \\
\hline & 34.42 & 2.6032 & 34.42 & 2.6033 & $\left(\begin{array}{lll}0 & 0 & 2\end{array}\right)$ \\
\hline & 36.23 & 2.4768 & 36.25 & 2.4759 & $\left(\begin{array}{lll}1 & 0 & 1\end{array}\right)$ \\
\hline & 47.49 & 1.9128 & 47.53 & 1.9111 & $\left(\begin{array}{lll}1 & 0 & 2\end{array}\right)$ \\
\hline & 56.64 & 1.6237 & 56.60 & 1.6247 & $\left(\begin{array}{lll}1 & 1 & 0\end{array}\right)$ \\
\hline & 62.82 & 1.4779 & 62.86 & 1.4771 & $\left(\begin{array}{lll}1 & 0 & 3\end{array}\right)$ \\
\hline & 67.84 & 1.3805 & 67.96 & 1.3781 & $\left(\begin{array}{lll}1 & 1 & 2\end{array}\right)$ \\
\hline \multirow{7}{*}{ AZ8-500 } & 31.74 & 2.8165 & 31.77 & 2.8143 & $\left(\begin{array}{lll}1 & 0 & 0\end{array}\right)$ \\
\hline & 34.40 & 2.6050 & 34.42 & 2.6033 & $\left(\begin{array}{lll}0 & 0 & 2\end{array}\right)$ \\
\hline & 36.23 & 2.4768 & 36.25 & 2.4759 & $\left(\begin{array}{lll}1 & 0 & 1\end{array}\right)$ \\
\hline & 47.56 & 1.9105 & 47.53 & 1.9111 & $\left(\begin{array}{lll}1 & 0 & 2\end{array}\right)$ \\
\hline & 56.53 & 1.6237 & 56.60 & 1.6247 & $\left(\begin{array}{lll}1 & 1 & 0\end{array}\right)$ \\
\hline & 62.86 & 1.4771 & 62.86 & 1.4771 & $\left(\begin{array}{lll}1 & 0 & 3\end{array}\right)$ \\
\hline & 68.15 & 1.3746 & 67.96 & 1.3781 & $\left(\begin{array}{lll}1 & 1 & 2\end{array}\right)$ \\
\hline
\end{tabular}


S. Kurtaran vd. / Fotovoltaik Güneş Pillerinde Saydam Ön Kontak Olarak Kullanılabilecek ZnO:Al Filmlerinin İncelenmesi

Tablo 3. Filmlerin tane boyutu, dislokasyon yoğunluğu ve makro gerilme değerleri.

\begin{tabular}{|c|c|c|c|}
\hline Malzeme & $\mathbf{D}(\mathbf{n m})$ & $\left.\mathbf{\delta} \mathbf{x} \mathbf{1 0}^{-\mathbf{4}} \mathbf{( n m}\right)^{-\mathbf{2}}$ & $<\mathbf{e}>\mathbf{\times 1 0 ^ { - 4 }}$ \\
\hline $\mathbf{A Z 8}$ & 45 & 4.9 & 6.5 \\
\hline $\mathbf{A Z 8 - 4 0 0}$ & 49 & 4.2 & -0.4 \\
\hline $\mathbf{A Z 8 - 5 0 0}$ & 44 & 5.1 & 6.5 \\
\hline
\end{tabular}

Al katkılı ZnO filmleri için yüksek sıcaklıklarda tavlama ile kristal seviyesi iyileștirilebilir ve tane boyutları azaltılabilir. $\mathrm{Bu}$ durumda saydam iletken oksitler için önemli bir parametre olan elektriksel özdirenç değerleri azaltılabilir. Ancak nadir de olsa literatürde yüksek sıcaklık tavlama işleminin tane boyutlarını azalttığı ve elektriksel özellikleri olumsuz yönde etkilediği çalışmalar mevcuttur $[3,47]$. $400{ }^{\circ} \mathrm{C}$ ' de tavlanan film için pik şiddetlerinin arttığl ve tane boyutunun büyüdüğü gözlenmiștir. Ancak $500{ }^{\circ} \mathrm{C}$ 'de tavlanan film için ise kristalleşmenin iyileștiğinden bahsetmek mümkün değildir. Tane boyutunda beklenen artışın görülmediği bu filmde üretim tekniğine bağlı olabilecek dezavantajlar ön plana çıkmış olabilir. UKP tekniğinde tamamlanmamış kimyasal reaksiyonlar neticesinde yapıda $\mathrm{AlCl}_{3}$ oluşumlarının kalması muhtemeldir. Hava ortamında yüksek sıcaklıkta $\left(500{ }^{\circ} \mathrm{C}\right.$ ve üzeri) yapılacak bir tavlama işleminde $2 \mathrm{AlCl}_{3}+$ $3 / 2 \mathrm{O}_{2} \rightarrow \mathrm{Al}_{2} \mathrm{O}_{3}+3 \mathrm{Cl}_{2}$ reaksiyonunun gerçekleşmesi ile arzu edilmeyen $\mathrm{Al}_{2} \mathrm{O}_{3}$ fazları tane büyümesini sınırlayabilir ve elektriksel özellikleri olumsuz yönde etkileyebilir. Buna ek olarak, elemental analiz sonuçları $500{ }^{\circ} \mathrm{C}$ 'de tavlanan bu film için $\mathrm{Al}$ elementinin atomik ağırlı̆̆ının diğer filmlere göre daha yüksek olduğunu göstermektedir. AZ8500 filmindeki yüksek tavlama sıcaklığı nedeniyle bulk bölgelerdeki Al atomlarının yüzeye göç ettiğini ve böylece $\mathrm{Al}$ elementine ait atomik ağırlık yüzdelerinin bu numune için daha yüksek çıktığını düşünmekteyiz. Bu durumda oksijen ile reaksiyona girebilecek $\mathrm{Al}$ elementi kolaylıkla $\mathrm{Al}_{2} \mathrm{O}_{3}$ fazlarına sebep olacak ve hem elektriksel özellikleri hem de yapısal özellikleri olumsuz yönde etkileyecektir.

\subsection{Optik Özellikler}

Al katkılı ZnO filmlerinin fotovoltaik güneş pillerinde ve optoelektronik aygıtlarda kullanım potansiyelini belirlemek için spektroskopik elipsometre ve UV spektrofotometre cihazları kullanılarak alınan ölçümlerden optik özellikleri incelenmiş ve tavlama sıcaklığının etkisi araştırılmıștır.

Spektroskopik elipsometre cihazı bir malzemenin kalınlığının hassas olarak belirlenmesine imkan sağladığı gibi, kırılma indisi ve sönüm katsayısı gibi optik sabitler hakkında da bilgi verir. Elipsometri tekniği ile elde edilen deneysel veriler, $\psi$ ve $\Delta$ parametreleri ile ifade edilir. Burada $\psi$ ve $\Delta$ yansıyan polarize ışığın genlik ve faz bilgileri ile ilgilidir. Bu iki katsayı numunenin optik özellikleri ve fiziksel boyutları hakkında bilgi içerir. Elipsometrik veri analizi, numunenin tabaka kalınlığ ve optik sabitlerini tanımlayan optik bir model gerektirir. $\mathrm{Bu}$ amaçla en çok kullanılan model Cauchy modelidir. Cauchy modeli malzemenin geçirgen olduğu optik bölgede kullanılır. Kırılma indisinin

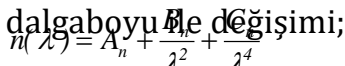

şeklinde verilir. Burada $A_{n}, B_{n}$ ve $C_{n}$ Cauchy parametreleridir. Sönüm katsayısının sıfır olduğu bölgelerde bu modelin kullanımı uygundur. Ancak, spektrumda sönüm katsayısının sıfır 
S. Kurtaran vd. / Fotovoltaik Güneş Pillerinde Saydam Ön Kontak Olarak Kullanılabilecek ZnO:Al Filmlerinin İncelenmesi

olmadı̆̆ ve az da olsa soğurmanın olduğu bölgeler bulunabilir. Bu durumda Cauchy modeline sönüm katsayısını tanımlayan bir denklem eklemek gerekir. Bu denklem Urbach denklemi olarak bilinir. Urbach denklemi malzemenin az bir soğurmaya sahip olduğu bölgede sönüm katsayısını $\underset{k(\lambda)}{\operatorname{temsil}}=A_{k} e^{B_{k}\left(E-E_{b}\right)}$

ifadesi ile verilir. Burada $A_{k}$ ve $B_{k}$ Urbach parametreleridir [48].

$\mathrm{Bu}$ çalışmada üretilen filmlerin kalınlıkları Cauchy-Urbach teorik modeli kullanılarak spektroskopik elipsometri tekniği ile belirlenmiştir. Filmlerin soğurma spektrumları da göz önüne alınarak her numune için soğurma katsayısının düşük olduğu uygun bir standart aralık 1300-1600 nm olarak belirlenmiștir. Ayrıca elipsometrik verilerin alınmasında depolarizasyon etkilerinden dolayı gelme açısının da etkisi büyüktür. Bu durum, numune yüzeyinden yansıyan ve analizöre ulaşan ışığın şiddet ve fazını etkilemektedir. Bu çalışmada filmler üzerine farklı gelme açılarında polarize ışı gönderilerek $\Delta$ spektrumları alınmıștır. $\quad \mathrm{Bu}$ spektrumlar değerlendirilerek ZnO filmleri için en uygun gelme açısı $65^{\circ}$ olarak saptanmiştır. Daha sonra en uygun gelme açısında ölçülen spektroskopik $\Delta$ değerlerinin, Cauchy-Urbach modeli kullanılarak teorik olarak belirlenen $\Delta$ değerleri ile en iyi uyumu (fitting) sağlanarak tüm filmlerin kalınlıkları hassas bir şekilde belirlenmiștir. Filmlerin deneysel ve teorik $\Delta$ spektrumları Şekil 2' de verilmektedir. Tüm filmlerin $\Delta$ spektrumlarından, teorik model ile deneysel veri arasındaki uyumun iyi olduğu görülmektedir ve Tablo 4' te verilen MSE (ortalama kare sapma) değerlerinin küçük olması da bu durumu desteklemektedir. Ancak, Şekil 2' de görüldüğü gibi, deneysel ve teorik
$\Delta$ değerlerinde bazı sapmalar da söz konusudur. $\mathrm{Bu}$ uyum işlemleri için korelasyon değerleri; AZ8, AZ8-400 ve AZ8-500 filmleri için sırası ile 0.957, 0.992 ve 0.961 olarak belirlenmiștir. UKP tekniği ile üretilen filmlerde pürüzlü yüzeylerle birlikte yüzeyde homojenliği bozan yı̆̆lma șeklinde kümelenmelerin olușması sıklıkla görülen durumlardır. Bundan dolayı sapmaların; üretim tekniğinden, yüzeylerindeki pürüzlülükten, yüzey etkilerinden ve tane sinırlarından kaynaklanabileceği söylenebilir. ZnO filmlerinin kalınlıkları $(t)$, modelleme parametreleri, ortalama kırılma indisi ve sönüm katsayısı değerleri Tablo 4' te verilmektedir.
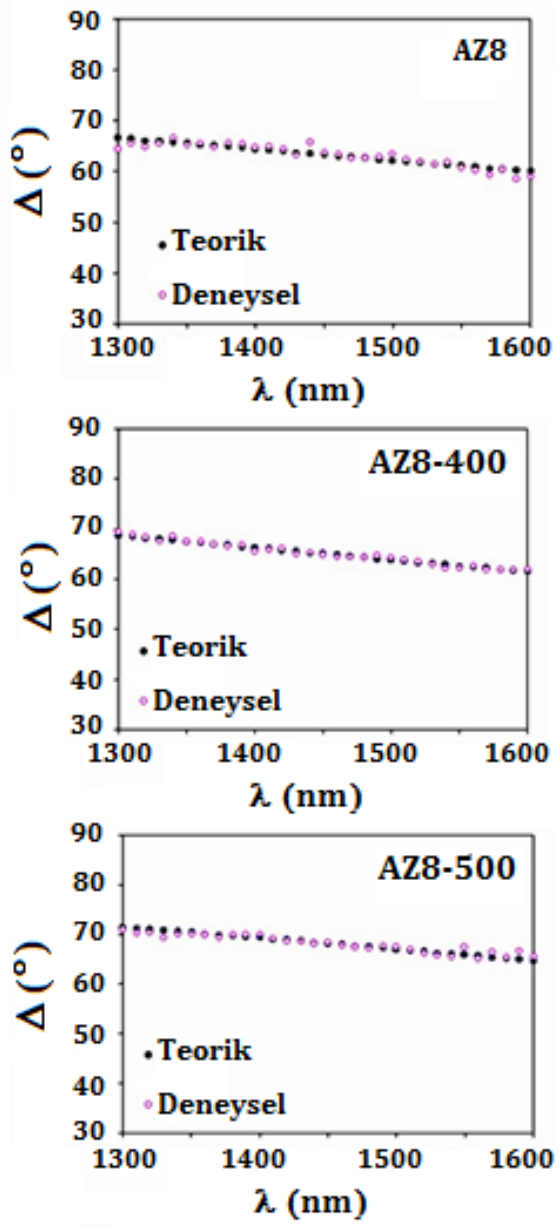

Şekil 2. Al katkılı $\mathrm{ZnO}$ filmlerinin $\Delta$ spektrumları. 
S. Kurtaran vd. / Fotovoltaik Güneş Pillerinde Saydam Ön Kontak Olarak Kullanılabilecek ZnO:Al Filmlerinin İncelenmesi

Tablo 4. Al katkılı ZnO filmlerinin kalınlık $(t)$ değerleri, model parametreleri, ortalama kırılma indisi $\left(n_{\text {ort }}\right)$ ve sönüm katsayısı (kort) değerleri.

\begin{tabular}{|c|c|c|c|}
\hline & AZ8 & AZ8-400 & AZ8-500 \\
\hline $\begin{array}{c}\mathbf{t} \\
(\mathbf{n m})\end{array}$ & 139 & 141 & 156 \\
\hline $\mathbf{A}_{\mathbf{n}}$ & 1.817 & 1.819 & 1.815 \\
\hline $\begin{array}{c}\mathbf{B}_{\mathbf{n}} \\
(\mathbf{n m})^{\mathbf{2}}\end{array}$ & 0.0001 & 0.0001 & 0.0001 \\
\hline $\begin{array}{c}\mathbf{C}_{\mathbf{n}} \\
(\mathbf{n m})^{\mathbf{4}}\end{array}$ & 0.001 & 0.001 & 0.001 \\
\hline $\mathbf{A}_{\mathbf{k}}$ & 0.116 & 0.106 & 0.101 \\
\hline $\begin{array}{c}\mathbf{B}_{\mathbf{k}} \\
(\mathbf{e V})-1\end{array}$ & 0.4 & 0.4 & 0.4 \\
\hline $\mathbf{n}_{\text {ort }}$ & 1.817 & 1.819 & 1.815 \\
\hline $\mathbf{k}_{\text {ort }}$ & 0.046 & 0.042 & 0.040 \\
\hline $\mathbf{M S E}$ & 0.13 & 0.41 & 0.64 \\
\hline
\end{tabular}

ZnO filmlerinin 350-800 $\mathrm{nm}$ dalgaboyu aralığında UV-VIS spektrofotometresi ile alınan geçirgenlik spektrumları Şekil 3' te verilmektedir. Spektrumlardan tüm filmlerin geçirgenlik değerlerinin uzun dalgaboylarında yüksek olduğu ve saydam malzemeler olarak davranış sergilediği görülmektedir. Ayrıca tavlama ișlemine tabi tutulmuș AZ8-400 ve AZ8-500 numunelerinde geçirgenlik değerinin arttığı dikkati çekmektedir. $\mathrm{Bu}$ duruma; tavlama işleminin etkisi ile filmlerin düzgün yüzey morfolojisine sahip olmaları ve yüzey pürüzlülüğünün azalması sebep olabilir.

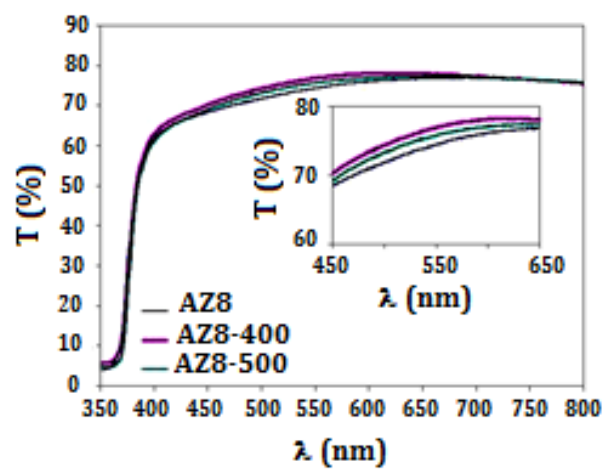

Şekil 3. Al katkılı ZnO filmlerinin geçirgenlik spektrumlarl.
ZnO filmlerinin optik bant aralıklarının belirlenebilmesi için optik metot kullanılmıștır. Bunun için; soğurma spektrumlarından faydalanılarak $\alpha=A / t$ ifadesinden her bir film için lineer soğurma katsayıları hesaplanıp, $(\alpha h v)^{2}$ nin $h v^{\prime}$ ye göre değișim grafikleri çizilmiştir. $\mathrm{Bu}$ grafiklerin lineer kısımlarının doğrultularının $h v$ eksenini $(\alpha h v)^{2}=0^{\prime}$ da kestiği noktaların enerji değerleri filmlerin optik bant aralıkları olarak belirlenmiştir. Al katkılı $\mathrm{ZnO}$ filmlerinin $(\alpha h v)^{2} \sim h v$ değişim grafikleri Şekil 4' te verilmektedir. Bu grafiklerden filmlerin direkt bant aralıklı malzemeler oldukları belirlenmiștir $[20,49]$. Bu özellik fotovoltaik güneș pili uygulamalarında istenen bir özelliktir. Al katkılı ZnO filmlerinin optik bant aralığı değerleri AZ8, AZ8-400 ve AZ8500 filmleri için sırası ile 3.292, 3.279 ve $3.278 \mathrm{eV}$ olarak belirlenmiștir ve bu değerler literatürle uyumludur $[35,41,50]$.
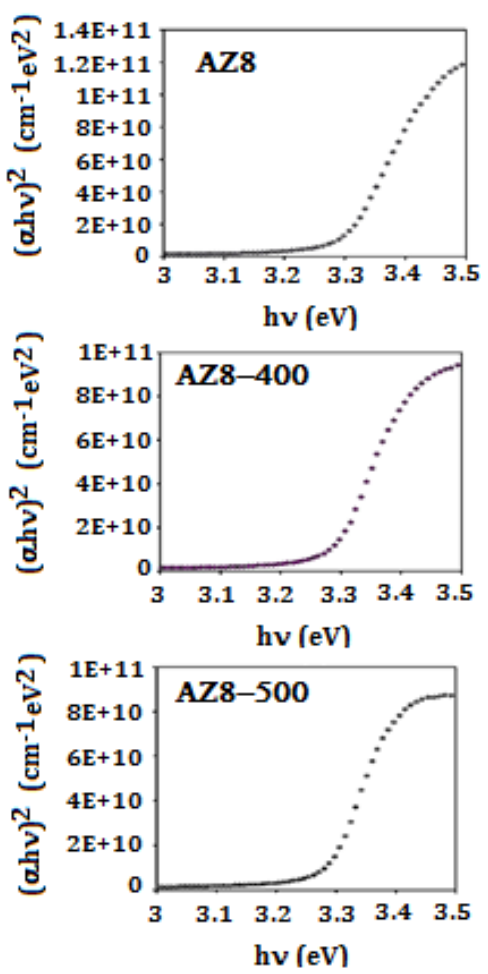

Şekil 4. Al katkılı ZnO filmlerinin $(\alpha h v)^{2} \sim$ $(h v)$ grafikleri. 
S. Kurtaran vd. / Fotovoltaik Güneş Pillerinde Saydam Ön Kontak Olarak Kullanılabilecek ZnO:Al Filmlerinin İncelenmesi

\subsection{Yüzeysel Özellikler}

Filmlerin üç boyutlu AKM görüntüleri Sekil 5 ' te verilmektedir. AKM görüntüleri incelendiğinde, özellikle isıl işlem görmeyen AZ8 filminin yüzeyinde rastgele dağılmış farklı yükseklik ve büyüklükte yığılmalar göze çarpmaktadır. Yüzeyde gözlenen bu beyaz bölgeler film oluşumu esnasında atomların üst üste yığılmaları sonucunda oluşan kümelerin bir göstergesidir. Bu yığılmaların tavlama işlemi ile etkisini kaybettiği görülmektedir. Bunun dışında tüm filmlerde ayırt edilebilir parçacıklardan olușan taneli bir yapılanmanın varlığı dikkat çekmektedir. AKM görüntülerinde dikkat çeken bir başka nokta ise tavlama işlemi ile film yüzeylerindeki parçacıkların iğne tipi bir oluşum sergileme eğiliminde olmalarıdır. Buna ek olarak tüm filmlerde parçacık boyutları 125-175 $\mathrm{nm}$ arasında değișmektedir. $\mathrm{Bu}$ değerlerin XIK ile elde edilen tane boyutu değerlerinden farklı olması beklenen bir durumdur. Çünkü buradaki parçacıklar iki veya daha fazla tanenin bir arada bulunabileceği yapılanmaları göstermektedir. Al katkılı $\mathrm{ZnO}$ filmlerinin $R q$ (rms) ve $R a$ (ortalama) pürüzlülük değerleri Tablo $5^{\prime}$ te verilmektedir.

Tablo 5. Al katkılı ZnO filmlerinin pürüzlülük değerleri.

\begin{tabular}{|l|l|l|}
\hline Malzeme & $\mathbf{R}_{\mathbf{a}}(\mathbf{n m})$ & $\mathbf{R}_{\mathbf{q}}(\mathbf{n m})$ \\
\hline $\mathbf{A Z 8}$ & 17 & 13 \\
\hline $\mathbf{A Z 8 - 4 0 0}$ & 15 & 12 \\
\hline AZ8-500 & 12 & 10 \\
\hline
\end{tabular}

\subsection{Elektriksel Özellikler}

Fotovoltaik uygulamalarda kullanılacak olan yariiletken filmlerin önemli bir diğer parametresi de elektriksel özellikleridir. Bir saydam iletken oksit olarak ZnO filmlerinin yüksek geçirgenlik yanında düşük elektriksel özdirenç değerlerine de sahip olması beklenir. Bu amaçla Al katkılı $\mathrm{ZnO}$ filmlerinin elektriksel özdirenç değerlerine tavlama sıcaklığının etkisini belirlemek için dört uç tekniği kullanılmıștır. AZ8, AZ8-400 ve AZ8-500 filmlerinin elektriksel özdirenç değerleri sırasiyla $3.3 \times 10^{0} \quad \Omega . \mathrm{cm}$, $4.2 \times 10^{2} \Omega . \mathrm{cm}$ ve $8.1 \times 10^{3} \Omega . \mathrm{cm}$ olarak belirlenmiștir. Elektriksel özdirenci düșük olan AZ8 filminin farklı sıcaklıklarda ısıl tavlanması ile özdirenç değerlerinde artış olduğu göze çarpmaktadır. XIK desenlerinin incelenmesi sonucunda hava ortamında $400{ }^{\circ} \mathrm{C}$ sicaklıkta tavlanan AZ8-400 filminde oksijen elementinin oksijen boşluklarının yerine geçerek kristalleşme seviyesinde iyileştirme etkisi yarattığı belirlenmişti. Buradan yola çlkarak AZ8-400 filminde donör etkisi yaratan oksijen boşluklarının azaldığını ve böylece taşıyıcı yoğunluğunun azalarak özdirenç değerlerinde artışa sebep olduğunu düşünmekteyiz. AZ8-500 filminin elektriksel özdirenç değerindeki artış ise, X-ışını kırınım desenlerine göre kristalleşme seviyesinin bozulmasından dolayı oksijen atomlarının oksijen boşluklarının yerine yerleşmesi yanında ara durum olarak ya da tane sinırlarına yerleșerek yapıya girmesinden kaynaklanabilir. Ara durum oksijen akseptör etkisi yaratarak taşıyıcı yoğunluğunun azalmasına ve böylece özdirenç değerlerinde artışa sebep olabilir. Tane sinırlarında oksijen fazlalığı ise saçılmalar yolu ile mobiliteyi azaltarak, AZ8-500 filminin daha yüksek özdirenç değerine sahip olmasına neden olabilir. Ayrıca daha önce de belirtildiği gibi, Al elementinin oksijen ile reaksiyona girmesi sonucu oluşabilecek $\mathrm{Al}_{2} \mathrm{O}_{3}$ fazları da özdirenç değerlerindeki artışın bir kaynağı olarak düşünülebilir. 
S. Kurtaran vd. / Fotovoltaik Güneş Pillerinde Saydam Ön Kontak Olarak Kullanılabilecek ZnO:Al Filmlerinin İncelenmesi

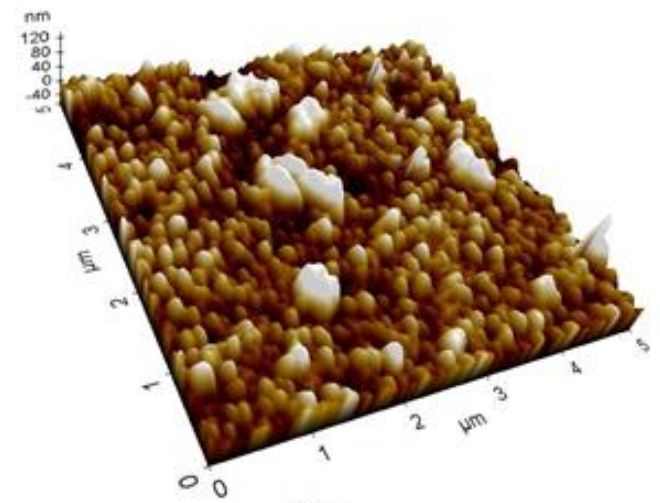

(a)

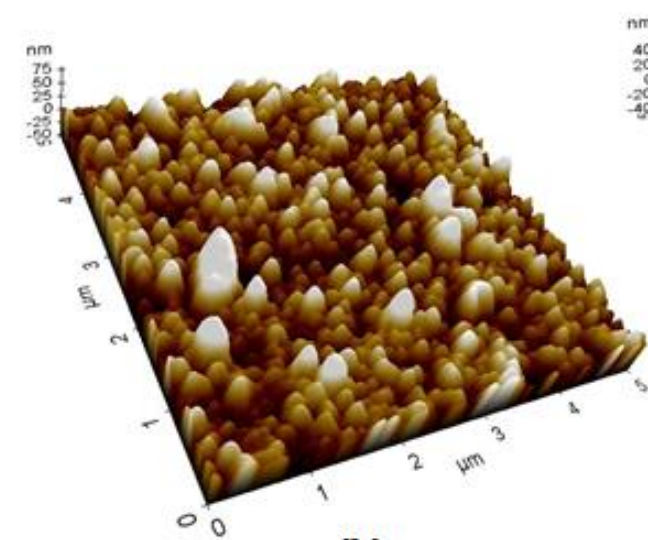

(b)

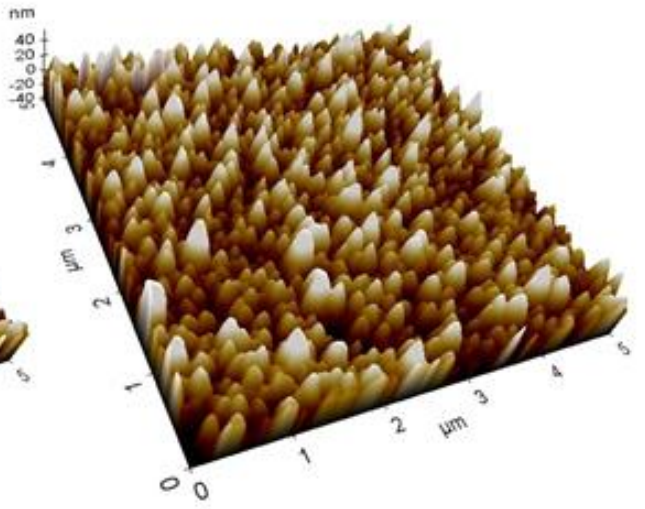

(c)

Şekil 5. Al katkılı ZnO filmlerinin AKM görüntüleri. (a) tavlanmamış (AZ8), (b) $400{ }^{\circ} \mathrm{C}$ (AZ8400) ve (c) $500^{\circ} \mathrm{C}(\mathrm{AZ8}-500)$ tavlanmış.

\section{Tartışma ve Sonuç}

$\mathrm{Bu}$ çalışmada basit ve ekonomik bir üretim tekniği olan ultrasonik kimyasal püskürtme tekniği ile üretilen Al katkılı ZnO filmlerinin yapısal, optik, elektriksel ve yüzeysel özellikleri üzerine tavlama sıcaklı̆̆ının etkisi incelenmiş ve teknolojik uygulamalarda özellikle de güneș pillerinde kullanım potansiyelleri araştırılmıştır. Filmlerin yapısal özelliklerinin incelenmesi sonucunda tavlama sıcaklığının filmlerin kristalleşme seviyeleri üzerinde önemli bir etkisi olduğu ve özellikle oksijen ve $\mathrm{Al}$ atomlarının yapıda yer bulmalarında farklı etkiler yarattığı tespit edilmiştir. $400{ }^{\circ} \mathrm{C}$ sicaklıkta tavlamanın etkisi ile tane sınırlarındaki oksijen miktarının azaldığı, oksijen atomlarının yapıdaki oksijen boşluklarının yerini işgal ederek kristalleşme seviyesini iyileştirdiği, ancak $500{ }^{\circ} \mathrm{C}$ sicaklıkta ise oksijen atomlarının daha çok ara durumlara ve tane sınırlarına yerleşerek kristalleşme seviyesinde bozulma etkisi yarattığı saptanmıştır. Yapısal özelliklerdeki bu değişimin doğrudan taşıyıcı yoğunluklarını azaltarak elektriksel özdirenç değerlerinde artışa sebep olduğu belirlenmiștir. Filmlerin optik özellikleri incelenerek tavlama ile optik geçirgenlik değerlerinin arttığı, ancak optik bant aralığı değerlerinde önemli 
S. Kurtaran vd. / Fotovoltaik Güneş Pillerinde Saydam Ön Kontak Olarak Kullanılabilecek ZnO:Al Filmlerinin İncelenmesi

bir değişim olmadı̆̆ı ve bu değerlerin literatürle uyumlu olduğu saptanmiştır. Filmlerin yüzey özelliklerinin incelenmesi sonucunda tavlama sıcaklığının yüzey morfolojisi üzerinde etkisi olduğu, tavlama işlemi ile filmlerde yığılma şeklindeki kümelenmelerin azaldığı ve iğne tipi bir yapılanmanın ortaya çıkmaya başladı̆̆ saptanmıștır. Yapılan incelemeler sonucunda tavlama sıcaklığının özellikle yapısal, yüzeysel ve elektriksel özellikler üzerinde önemli bir etki yarattığı ve teknolojik uygulamalar için $400{ }^{\circ} \mathrm{C}$ tavlama sıcaklığının uygun olduğu sonucuna varılmıştır.

\section{KAYNAKÇA}

[1] Xu J., Wang H., Yang L., Jiang M., Wei S., Zhang T. 2010. Low temperature growth of highly crystallized ZnO:Al films by ultrasonic spray pyrolysis from acetylacetone salt: Materials Science and Engineering B, Cilt. 167, s. 182-186. DOI:10.1016/j.mseb.2010.02.012

[2] Park T., Park N., Kim J., Lee W., Lee S. 2015. Cross plane temperature dependent thermal conductivity of Al-doped zinc oxide thin films: Journal of Alloys and Compounds, Cilt. 638, s. 83-87.

DOI:10.1016/j.jallcom.2015.03.065

[3] El Manouni A., Manjon F. J., Perales M., Mollar M., Mari B., Lopez M. C., Barrado J. R. R. 2007. Effect of thermal annealing on $\mathrm{ZnO}$ :Al thin films grown by spray pyrolysis: Superlattices and Microstructures, Cilt. 42, s. 134-139.

DOI: 10.1016/j.spmi.2007.04.005

[4] El Manouni A., Manjón F. J., Mollar M., Marí B., Gómez R., López M.C., Barrado J. R. R. 2006. Effect of aluminium doping on zinc oxide thin films grown by spray pyrolysis: Superlattices and
Microstructures, Cilt. 39, s. $185-$ 192.

DOI: 10.1016/j.spmi.2005.08.041

[5] Yan M., Zhang H. T., Widjaja E. J., Chang R. P. H. 2003. Self-assembly of well aligned gallium-doped zincoxide nanorods: Journal of Applied Physics, Cilt. 94, s. 5240-5246. DOI: $10.1063 / 1.1608473$

[6] Wang H., Baek S., Song J., Lee J., Lim S. 2008. Microstructural and optical characterisitics of solutiongrown Ga-doped $\mathrm{ZnO}$ nanorod arrays: Nanotechnology, Cilt. 19, s. 075607-075613.

DOI:10.1088/09574484/19/7/075607

[7] Bie X., Lu J. G., Gong L., Lin L., Zhao B. H., Ye Z. Z. 2009. Transparent conductive $\mathrm{ZnO}$ :Ga films prepared by DC reactive magnetron sputtering at low temperature: Applied Surface Science, Cilt. 256, s. 289-293.

DOI:10.1016/j.apsusc.2009.08.018

[8] Liu C., He H., Sun L., Yang Q., Ye Z., Chen L. 2011. Acceptor-related emissions in indium-doped $\mathrm{ZnO}$ nanorods: Journal of Applied Physics, Cilt. 109, s. 053507053511.

DOI:10.1063/1.3552981

[9] Liu K. W., Sakurai M., Aono M. 2010. Indium doped ZnO nanowires: Optical properties and room temperature ferromagnetism Journal of Applied Physics, Cilt. 108, s. 043516-043521. DOI:10.1063/1.3464229

[10] Wu Z. F., Wu X. M., Zhung L. J., Hong B., Yang X. M., Chen X. M., Chen Q. 2010. Synthesis and magnetic properties of $\mathrm{Mn}$-doped $\mathrm{ZnO}$ nanorods via radio frequency plasma deposition: Materials Letters, Cilt. 64, s. 472- 474. DOI: $10.1016 /$ j.matlet.2009.11.053 
S. Kurtaran vd. / Fotovoltaik Güneş Pillerinde Saydam Ön Kontak Olarak Kullanılabilecek ZnO:Al Filmlerinin İncelenmesi

[11] Mohanta A., Thareja R. K. 2010. Temperature-dependent S-shaped photoluminescence in $\mathrm{ZnCdO}$ alloy: Journal of Applied Physics, Cilt. 107: 084904, s. $1-4$. DOI: $10.1063 / 1.3391067$

[12] Te-Hua F., Shao-Hui K. 2010. Preparation and characterisation of Mg-doped $\mathrm{ZnO}$ nanorods: Journal of Alloys and Compounds, Cilt. 492, s. 536- 542.

DOI:10.1016/j.jallcom.2009.11.168

[13] Narayan J., Sharma A. K., Kvit A., Jin C., Muth J., Holland O. 2001. Novel cubic $\mathrm{Zn}_{\mathrm{x}} \mathrm{Mg}_{1-\mathrm{x}} \mathrm{O}$ epitaxial hetero structures on Si ( $\left.\begin{array}{lll}1 & 0 & 0\end{array}\right)$ substrates: Solid State Communications, Cilt. 121, s. 9-13.

DOI:10.1016/S0038-

1098(01)00431-8

[14] Kurtaran S., Aldag S., Ofofoglu G., Akyuz I., Atay F. 2016. Transparent conductive $\mathrm{ZnO}$ thin films grown by chemical spray pyrolysis: The effect of Mg: Journal of Materials Science: Materials in Electronics, Cilt. 27 (8), s. 8478-8485.

DOI: $10.1007 / s 10854-016-4862-1$

[15] Wang X., Xu J., Yu X., Xue K., Yu J., Zhao X. 2007. Structural evidence of secondary phase segregation from the Raman vibrational modes in $\mathrm{Zn}_{1-x} \mathrm{Co}_{\mathrm{x}} \mathrm{O} \quad(0<x<0.6)$ : Applied Physics Letters, Cilt. 91, s. 031908031910.

DOI:10.1063/1.2759272

[16] Vimalkumar T. V., Poornima N., Jinesh K. B., Sudha K. C., Vijayakumar K. P. 2011. On single doping and Co-doping of spray pyrolysed ZnO films: Structural, electrical and optical characterization: Applied Surface Science, Cilt. 257, s. 8334-8340. DOI:10.1016/j.apsusc.2011.03.118

[17] Yang J., Lee J., Im K., Lim S. 2009. Influence of $\mathrm{Sn}$ doping in hydrothermal methods on the optical property of the $\mathrm{ZnO}$ nanorods: Physica E, Cilt. 42, s. 51 56.

DOI:10.1016/j.physe.2009.08.018

[18] Srinivasan G., Kumar R. T., Kumar J. 2007. Influence of $\mathrm{Al}$ dopant on microstructure and optical properties of $\mathrm{ZnO}$ thin films prepared by sol-gel spin coating method: Optical Material, Cilt. 30, s. 314- 317.

DOI:10.1016/j.optmat.2006.11.075

[19] Lee J. H., Chou C. Y., Bi Z., Tsai C. F., Wang H. 2009. Growth-controlled surface roughness in $\mathrm{Al}$-doped $\mathrm{ZnO}$ as transparent conducting oxide: Nanotechnology, Cilt. 20, s. 395704-395711.

DOI: $10.1088 / 0957-$

4484/20/39/395704

[20] Shan F. K., Yu Y. S. 2004. Band gap energy of pure and Al-doped $\mathrm{ZnO}$ thin films: Journal of the European Ceramic Society, Cilt. 24, s. 1869 1872. DOI:10.1016/S09552219(03)00490-4

[21] Suwanboon S., Amornpitoksuk P., Haidoux A., Tedenac J. C. 2008. Structural and optical properties of undoped and aluminium doped zinc oxide nanoparticle: Journal of Alloys and Compounds, Cilt. 462, s. 335-339.

DOI:10.1016/j.jallcom.2007.08.048

[22] Sharma B. K., Khare N. 2010. Stress-dependent band gap shift and quenching of defects in Aldoped ZnO films: Journal of Physics D Applied Physics, Cilt. 43, s. 465402-465408. DOI:10.1088/00223727/43/46/465402

[23] Kumar R. S., Sathyamoorthy R., Sudhagar P., Matheswaran P., Hrudhya C. P., Kang Y. S. 2011. 
S. Kurtaran vd. / Fotovoltaik Güneş Pillerinde Saydam Ön Kontak Olarak Kullanılabilecek ZnO:Al Filmlerinin İncelenmesi

Effect of aluminum doping on the structural and luminescent properties of $\mathrm{ZnO}$ nanoparticles synthesized by wet chemical method: Physica E, Cilt. 43, s. 11661170.

DOI:10.1016/j.physe.2011.01.022

[24] Venkatachalam S., Iida Y., Kanno Y. 2008. Preparation and characterization of Al-doped $\mathrm{ZnO}$ thin films by PLD: Superlattices and Microstructures, Cilt. 44, s. 127- 135.

DOI:10.1016/j.spmi.2008.03.006

[25] Liu S. P., Wuu D. S., Ou S. L., Fu Y. C., Lin P. R., Hung M. T., Horng R. H. 2011. Highly ultraviolet transparent ZnO:Al conducting layers by pulsed laser deposition: Journal of The Electrochemical Society, Cilt. 158, s. K127-K130. DOI:10.1149/1.3567025

[26] Singh A. V., Kumar M., Mehra R. M., Wakahara A., Yoshida A. 2001. Aldoped zinc oxide ( $\mathrm{ZnO}: \mathrm{Al})$ thin films by pulsed laser ablation: Journal of the Indian Institute of Science, Cilt. 81, s. 527-533.

[27] Kim K. H., Park K. C., Ma D. Y. 1997. Structural, electrical and optical properties of aluminum doped zinc oxide films prepared by radio frequency magnetron sputtering: Journal of Applied Physics, Cilt. 81, s. 7764. DOI:10.1063/1.365556

[28] Yuldashev S. U., Kang T. W., Pelenovich V. O., Uygun V. V. 2009. Photoluminescence and Magnetooptical Properties of $\mathrm{Zn}_{1-\mathrm{x}} \mathrm{Mn}_{\mathrm{x}} \mathrm{O}$ : Journal of the Korean Physical Society, Cilt. 55(3), s. 938-941. DOI: $10.3938 /$ jkps.55.938

[29] Kim H., Horwitz J. S., Qadri S. B., Chrisey D. B. 2002. Epitaxial growth of Al-doped $\mathrm{ZnO}$ thin films grown by pulsed laser deposition:
Thin Solid Films, Cilt. 420-421, s. 107-111.

DOI:10.1016/S00406090(02)0065

8-2

[30] Xue S. W., Zu X. T., Zheng W. G., Chen M. Y., Xiang X. 2006. Effects of annealing and dopant concentration on the optical characteristics of $\mathrm{ZnO}$ : Al thin films by sol-gel technique: Physica B: Condensed Matter, Cilt. 382, s. 201204.

DOI:10.1016/j.physb.2006.02.032

[31] Rao T. P., Kumar, M. C. S., Hussain N. S. 2012. Effects of thickness and atmospheric annealing on structural, electrical and optical properties of GZO thin films by spray pyrolysis: Journal of Alloys and Compounds, Cilt. 541, s. 495 504.

DOI:10.1016/j.jallcom.2012.05.128

[32] Guild C., Biswas S., Meng Y., Jafari T., Gaffney A. M., Suib S. L. 2014. Perspectives of spray pyrolysis for facile synthesis of catalysts and thin films: An introduction and summary of recent directions: Catalysis Today, Cilt. 238, s. 87-94. DOI:10.1016/j.cattod.2014.03.056

[33] Benzarouk H., Drici A., Mekhnache M., Amara A., Guerioune M., Bernède J. C., Bendjffal H. 2012. Effect of different dopant elements (Al, Mg and $\mathrm{Ni}$ ) on microstructural, optical and electrochemical properties of $\mathrm{ZnO}$ thin films deposited by spray pyrolysis (SP): Superlattices and Microstructures, Cilt. 52, s. 594-604.

DOI:10.1016/j.spmi.2012.06.007

[34] Nambala F. J., Nel J. M., Augusto G. J. M., Bonex W. M., Eric G. N., Maabong K., Das A. G. M., Diale M. 2016. Role of substrate and annealing temperature on the structure of $\mathrm{ZnO}$ and $\mathrm{Al}_{\mathrm{x}} \mathrm{Zn}_{1-\mathrm{x}} \mathrm{O}$ thin 
S. Kurtaran vd. / Fotovoltaik Güneş Pillerinde Saydam Ön Kontak Olarak Kullanılabilecek ZnO:Al Filmlerinin İncelenmesi

films for solar cell applications: Physica B, Cilt. 480, s. 72-79. DOI:10.1016/j.physb.2015.09.022

[35] Shivaraj B. W., Murthy H. N., Krishna M., Satyanarayana B. S. 2015. Effect of Annealing Temperature on Structural and Optical properties of Dip and Spin coated ZnO Thin Films: Procedia Materials Science, Cilt. 10, s. 292 300.

DOI:10.1016/j.mspro.2015.06.053

[36] Podobinski D., Zanin S., Pruna A., Pullini D. 2013. Effect of annealing and room temperature sputtering power on optoelectronic properties of pure and Al-doped ZnO thin films: Ceramics International, Cilt. 39 (2), s. 10211027.

DOI:10.1016/j.ceramint.2012.07.0 22

[37] Liu C., Xu Z., Zhang Y., Fu J., Zang S., Zuo Y. 2015. Effect of annealing temperature on properties of ZnO:Al thin films prepared by pulsed DC reactive magnetron sputtering: Materials Letters, Cilt. 139, s. 279-283.

DOI:10.1016/j.matlet.2014.10.106

[38] Wang F., Wu M. Z., Wang Y. Y., Yu Y. M., Wu X. M., Zhuge L. J., 2013. Influence of thickness and annealing temperature on the electrical, optical and structural properties of AZO thin films: Vacuum, Cilt. 89, s.127-131. DOI: 10.1016/j.vacuum.2012.02.040

[39] Surajit G., Chakraborty J. 2016. Obviating the post annealing step for production of Al-doped zinc oxide films using sol-gel method: Use of rapid cooling and gas blanketing: Thin Solid Films, Cilt. 605, s. 173-179. DOI: 10.1016/j.tsf.2015.09.062
[40] Flickyngerova S., Netrvalova M., Prusakova L., Novotny I., Sutta P., Tvarozek V. 2010. Modification of AZO thin-film properties by annealing and ion etching: Vacuum, Cilt. 84, s. 215-217. DOI: 10.1016/j.vacuum.2009.04.006

[41] Lee J. H., Park B. O. 2004. Characteristics of $\mathrm{Al}$-doped $\mathrm{ZnO}$ thin films obtained by ultrasonic spray pyrolysis: effects of $\mathrm{Al}$ doping and an annealing treatment: Materials Science and Engineering: B, Cilt. 106, s. $242-$ 245.

DOI:10.1016/j.mseb.2003.09.040

[42] Prepelita P., Craciun V., Garoi F., Staicu A. 2015. Effect of annealing treatment on the structural and optical properties of AZO samples: Applied Surface Science, Cilt. 352, s. 23-27.

DOI: 10.1016/j.apsusc.2015.02.089

[43] Atay F., Kose S., Bilgin V., Akyuz I. 2003. CdS:Ni films obtained by ultrasonic spray pyrolysis: effect of the $\mathrm{Ni}$ concentration: Materials Letters, Cilt. 57, s. 3461-3472. DOI: 10.1016/S0167-577X(03)00100-9

[44] Kaelble E. F. (Ed), 1967. Handbook of X-rays for diffraction, emission, absorption and microscopy, McGraw-Hill, New York, 25s.

[45] Zhao Z., Morel D. L., Ferekides C. S. 2002. Electrical and optical properties of thin-doped CdO films deposited by atmospheric metalorganic chemical vapour deposition: Thin Solid Films, Cilt. 413, s. 203-211. PII: S0040-6090Ž0 $2.00344-9$

[46] Vigil O., Vaillant L., Cruz F., Santana G., Morales-Acevedo A., ContrerasPuente G. 2000. Spray pyrolysis deposition of cadmium-zinc oxide thin films: Thin Solid Films, Cilt. 
S. Kurtaran vd. / Fotovoltaik Güneş Pillerinde Saydam Ön Kontak Olarak Kullanılabilecek ZnO:Al Filmlerinin İncelenmesi

361-362, s. 53-55. PII: S00406090(99)01061-5.

[47] Thida W., Than T. W., Yin M. M., Ko K. K. S. 2013. Effect of Annealing Temperature on photovoltaic Parameters of $\mathrm{Al}$ doped $\mathrm{ZnO}$ Thin Film Solar Cell, PCO Proceding on AIP Guide, Vol:2008 ISBN: 978983-44483-63.

[48] Khoshman, J. M., Kordesch M. E. 2005. Spectroscopic ellipsometry characterization of amorphous aluminum nitride and indium nitride thin films: Physica Status Solidi (C), Cilt. 2, s. 2821-2827. DOI: 10.1002 pssc.200461331

[49] Babu B. J., Maldonado A., Velumani S., Asomoza R. 2010. Electrical and optical properties of ultrasonically sprayed $\mathrm{Al}$-doped zinc oxide thin films: Materials Science and Engineering B, Cilt. 174, s. 31-37. DOI:10.1016/j.mseb.2010.03.010

[50] Gençyılmaz O., Atay F., Akyüz I. 2016. Deposition and Ellipsometric Characterization of Transparent Conductive Al-doped $\mathrm{ZnO}$ for Solar Cell Application: Journal of Clean Energy Technologies, Cilt. 4 (2), s. 90-94.

DOI: 10.7763/JOCET.2016.V4.259 